\title{
Assessment of inventory and store management practices of pharmaceuticals in public health centers and hospitals of Dessie Town, Ethiopia
}

Ewunetie Mekashaw Bayked ( $\nabla$ mekashawe@gmail.com )

Wollo University

Mesfin Haile Kahissay

Wollo University

Birhanu Demeke Workneh

Wollo University

Research article

Keywords: Inventory management, inventory record, Store management, pharmaceuticals, Public health institution

Posted Date: September 11th, 2019

DOI: https://doi.org/10.21203/rs.2.14307/v1

License: (c) (i) This work is licensed under a Creative Commons Attribution 4.0 International License. Read Full License 


\section{Abstract}

Background: Inventory management is the safe practice of proper storage, distribution of items and accurate record keeping. It is the pumping organ of the drug supply system without which the whole health care service will collapse. The purpose of this study was so to assess inventory and store management practices of pharmaceuticals in public health centers and hospitals of Dessie Town, Ethiopia. Method: The study was conducted from February 5 to 24, 2019. The study design was institution based cross sectional study. Data were collected by observation check lists. 10 health institutions ( 2 hospitals and 8 health centers) were studied. Result: Receipts, issues, losses and adjustments were correctly recorded in 7 stores but with calculation fallacies. Invoices and bin cards were available in all stores. Logistic management and information system, Internal Facility Report and Resupply, and Report and Requisition Form were available in 9 stores. 5 stores had stock cards but only 3 recorded prices correctly on it. The maximum, minimum, re-order and buffer stocks levels were not properly maintained and automated in all stores. All stores had freezers but wall thermometers and lockable cabinets were absent in 8 stores; most $(n=7)$ did not use First Expired, First out storage technique. Humidity and fire control mechanisms were absent in all and seven institutions respectively; however, 9 institutions lack fire proof areas for combustibles but 8 stores held them with drugs. Conclusion: The inventory and store management practices of the institutions were not satisfactory. The major problems in these institutions were calculation and recording errors; stock maintenance problem; lack of automation in recording; absence of wall thermometers, humidity and fire control systems and lockable cabinets; fail to use First Expired, First out storage technique and holding combustibles with drugs.

\section{Background}

Inventory management is all about ordering, receiving, storing, issuing and reordering of items. It is not an easy task; actually critical and complex. It hosts storage, distribution [1] and accurate record keeping [1-3]. It is a system of transaction and healthy stock keeping practice of commodities [3]. It ultimately requires morally and legally sound recording practice. Inventory control and recording are thus inseparable. Thus, stock records are the core records in the inventory management system. They can be either manual or computerized [2,3]. Common inventory recording and documentation formats are Internal Facility Report and Resupply Form (IFRR) and Report and Requisition Form (RRF) [2], Bin Card (BC), Stock Record Card (SRC) [1-3]. These records are collectively referred to as inventory or stock records. Stock records are sources of basic and primary information for inventory management in that they contain all transactions of individual units. They provide information on inventory receipts, issues, losses, orders and balances, suppliers, customers and prices. The information they contain is used to compile and generate performance reports and various reordering formulas respectively. The information inferred from them is essential for planning distribution and quantification. They are thus at the center of inventory management system; they are mandatory, not optional [3]. 
Inventory control also hosts good store management strategy. Without proper handling and storing, inventory maintenance is unthinkable. Pharmaceuticals should be protected from sun, heat, and water; should be stored and kept in good condition as far as their character permits [2-5]. Products should always be kept in a manner to facilitate the first-to-expire, first-out (FEFO) procedure [6]. All products should be stored in a well-organized store at their temperature requirement, in humidity not more than $60 \%$ moisture content $[4,7]$.

From any point of view, without efficient inventory management, patient safety will not be guaranteed [8]. It is a tool to optimize conflicting fluctuations of stocks [9]. However, discrepancies of actual and recorded counts are common in Ethiopia, about 60\% [10] which dictates to have clean/accurate inventory records [11] with automated system [12]. Expiry and stock out of vital medicines are substantial [10]; poor inventory control system is the main reason for wastage and shortage of essential medicines [13] due to stock-outs [14] because of poor inventory control [15]. On the other hand, the leading causes of morbidity and mortality in developing countries like Ethiopia are easily curable diseases by these vital medicines [14]. Hence, the success of healthcare sector cannot be realistic without efficient and effective inventory management [16]. However, in Sub-Saharan Africa, stock-outs are major causes of health care service interruptions [17]. Generally, inventory management system is at its primitive nature by any yardstick in Sub-Saharan African countries like Ethiopia. Thus, the objective of this study was to assess inventory and store management practices of pharmaceuticals in public health centers and hospitals of Dessie Town, Ethiopia.

\section{Methods}

\section{Study area and design}

The study was conducted in two public hospitals and 8 public health centers of Dessie, Ethiopia from February 5 to 24, 2019. Dessie is an administrative Town in Amhara regional state. It is located to the North East of the capital Addis Ababa 401 kilometers away. All public health institutions which are mandated to held stock of pharmaceuticals included except community pharmacies owned by government. The study also not included health posts as they had no grant to hold pharmaceutical stocks. Institution based cross sectional study design was conducted with observation check lists by extrapolating criteria from standard documents of World Health Organization (WHO), United States Agency for International Development (USAID) deliver projects and Ethiopian Pharmaceuticals Supply Agency (EPSA). The check lists were prepared in a manner to include all components of inventory management like stock transaction, storage control and management, recording systems and handling.

\section{Data collection and analysis}

The data were collected by using observation check lists at the central stores of all institutions through direct observation and analysis of inventory transaction indicators from records, inventory record forms and models, recording status, storage organization and arrangement, furnishing and functionality of quality control tools in the stores. All records and documents available have been observed and reviewed. 
Any technologies that are important for inventory management system has been sought for availability and functionality; automation status and data interchange technology and reporting systems. Data quality assurance measure was taken before, during and after data collection for the completeness, clarity and legibility of checklists. The collected data was held confidentially. Finally, the data were analyzed and completed by using Microsoft Office Excel 2010 worksheet.

\section{Results}

\section{Inventory management methods and transaction}

As it is illustrated in table 1, among the central stores of all 10 institutions, none of stores had maintained maximum, minimum, and re-order stock levels as well as maintained safety stock level to prevent stock outs. Three of the institutions did not properly record receipts, issues, losses and adjustments. None of the institutions did have automated stock transaction method or inventory management software in their central store. There was incidence of stock outs in six institutions during the last three months. On the other hands three institutions had experience of over stock in the last three months. There were expired commodities in four of the institutions in the last three months. Two institutions did not have standard guide line for commodities inventory management. In six of the institutions, quantities on inventory records were properly matched with the physical count. Three institutions had appropriately recorded price of each item on stock record card.

Table 1: Pharmaceuticals inventory management methods and transaction in 10 public health institutions of Dessie Town, February 2019

\begin{tabular}{|c|l|c|c|}
\hline S.No & \multicolumn{1}{|c|}{ Activities } & \multicolumn{2}{|c|}{$\begin{array}{c}\text { Response in } \\
\text { No }\end{array}$} \\
\cline { 3 - 4 } & & \multicolumn{1}{|c|}{ Yes } & No \\
\hline 1 & $\begin{array}{l}\text { Records reflect Maximum, Minimum and Re-order levels } \\
\text { maintained }\end{array}$ & 0 & 10 \\
\hline 2 & Tools dictate safety stock maintenance to prevent stock out & 0 & 10 \\
\hline 3 & Receipts, issues, losses and adjustments properly recorded & 7 & 3 \\
\hline 4 & Automated stock transaction available & 0 & 10 \\
\hline 5 & Incidence of stock outs during the last three months & 6 & 4 \\
\hline 6 & Experience of over stock in the last three months & 3 & 7 \\
\hline 7 & The presence of expired commodities in the last three months & 4 & 6 \\
\hline 8 & $\begin{array}{l}\text { Standard guide line for commodities inventory management } \\
\text { available }\end{array}$ & 8 & 2 \\
\hline 9 & Quantities on inventory records match with the physical count & 6 & 4 \\
\hline 10 & Price of each item properly recorded on stock record card & 3 & 7 \\
\hline
\end{tabular}




\section{Recording and documentation}

Regarding to recording and documentation status, as it is depicted clearly in table 2, bin cards and invoices (model 19 or receipt invoice and 22 or issuing invoice) were available and used in all institutions whereas stock cards were available in 5 of the institutions. Nine of them had and used RRF and IFRR. Six institutions had separate records for all items. Three of the institutions had detailed written inventory instructions and procedures. Logistic management and information system (LMIS) formats and job aids were available in nine institutions. Neither of the institutions had electronic data interchange technology system nor maintained a data base of their suppliers.

Table 2: Recording and documentation status of the pharmaceuticals inventory management in 10 public health institutions of Dessie Town, February 2019

\begin{tabular}{|c|l|c|c|}
\hline S.No & \multicolumn{1}{|c|}{ Activities } & \multicolumn{2}{c|}{ Response in No } \\
\cline { 3 - 4 } & & Yes & No \\
\hline 1 & Availability and proper utilization of BC & 10 & 0 \\
\hline 2 & Presence and utilization of SRC & 5 & 5 \\
\hline 3 & Availability and utilization of RRF & 9 & 1 \\
\hline 4 & IFRR formats available and filled properly & 9 & 1 \\
\hline 5 & Vouchers (Model 19 and 22) available and properly used & 10 & 0 \\
\hline 6 & Maintain separate records for all commodities & 6 & 4 \\
\hline 7 & Detailed written inventory instructions and procedures exist & 3 & 7 \\
\hline 8 & The institution maintains a data base for their suppliers & 0 & 10 \\
\hline 9 & LMIS formats and job Aids available & 9 & 1 \\
\hline 10 & Electronic Data Interchange Technology available & 0 & 10 \\
\hline
\end{tabular}

\section{Store management}

The store of two institutions completely controlled and operated by pharmacists and all the rest were operated by druggists. Only two institutions had functional wall thermometers to control room temperature. None of the institutions had calibrated hygrometer to control humidity. Fire extinguishers were not available in seven institutions to be used in case of fire emergency. Only one institution had fire proof area for combustible substances. The stores of six institutions were properly shelved, clean \& dry, ventilated \& out of direct sunlight. Lockable cabinets for controlled drugs storage were not available in eight institutions. All of the institutions had cold storage facilities for vaccines \& biological products. Three of the institutions used FEFO storage technic to track out items. The store room of one institution was not protected from water penetration. In the stores of seven institutions, cartons were stacked at 
least $10 \mathrm{~cm}$ off the floor whereas cartons in three institutions were visible at the floor. Each shelf arranged $30 \mathrm{~cm}$ away from the wall and other stacks only in the stores of two institutions; but arranged in others with no space between. Cartons stacked no more than $2.5 \mathrm{~m}$ high in six of the institutions but contact of cartons with ceiling was visible in four of them. Cartons were arranged with arrows pointing up, and with identification labels, expiry dates and manufacturing dates clearly visible in five of the institutions but arranged haphazardly in others. Damaged or expired products were properly separated, sorted and labeled in seven institutions. Non-pharmaceutical products were stored along with drugs in four institutions. Corrosives and combustibles held separately only in two of the institutions. Six of the institutions had sufficient space for free tracking of goods in their stores (refer to table 3 ).

Table 3: Store management situation of pharmaceuticals in 10 public health institutions of Dessie Town, February 2019

\begin{tabular}{|c|l|c|c|}
\hline S.No & \multicolumn{1}{|c|}{ Activities } & \multicolumn{1}{|c|}{ Response in } \\
& & Yos & No \\
\cline { 2 - 4 } & & 2 & 8 \\
\hline 1 & Store completely controlled and operated by pharmacist & 2 & 8 \\
\hline 2 & Availability of functional wall thermometer & 0 & 10 \\
\hline 3 & Calibrated hygrometer available in store & 3 & 7 \\
\hline 4 & Presence of fire extinguishers in case of fire emergency & 1 & 9 \\
\hline 5 & Fire proof areas for combustible substances & 6 & 4 \\
\hline 6 & Store properly shelved, clean, dry, ventilated \& out of direct & & \\
\hline 7 & sunlight & 2 & 8 \\
\hline 8 & Cold storage facilities for vaccines \& biological products & 10 & 0 \\
\hline 9 & Storage by using FEFO technique & 3 & 7 \\
\hline 10 & Store room protected from water penetration & 9 & 1 \\
\hline 11 & Cartons stacked at least 10 cm off the floor & 7 & 3 \\
\hline 12 & Each shelf arranged 30 cm away from the wall and other stacks & 2 & 8 \\
\hline 13 & Cartons stacked no more than 2.5m high & 6 & 4 \\
\hline 14 & $\begin{array}{l}\text { Cartons placed with arrows up, labeled \& expiry dates clearly } \\
\text { visible }\end{array}$ & 5 & 5 \\
\hline 15 & $\begin{array}{l}\text { Separation of damaged or expired products and removal from } \\
\text { stock }\end{array}$ & 7 & 3 \\
\hline 16 & Storage of non-pharmaceutical products with drugs & 4 & 6 \\
\hline 17 & Corrosives and combustibles held separately & 2 & 8 \\
\hline 18 & Sufficient space for free tracking of items & 6 & 4 \\
\hline
\end{tabular}

\section{Discussion}


Findings from this study revealed that records in all institutions dictate that they did not actually maintain the maximum, minimum, re-order and buffer stocks levels to facilitate smooth stock flow. They did not put a bench mark to the amount of these levels by time. Similarly, an indicator based assessment of medicine storage and inventory management in India showed that none of the institutions demarcated maximum and minimum stock levels [18]. This may be due to fluctuations in stock levels. Receipts, issues, losses and adjustments were properly recorded in most of institutions $(n=7)$ with calculation fallacies but none of the institutions automated their transaction system which is similar to the study conducted on pharmaceutical store management in West Hararghe Zone, Ethiopia [5] that might be due to lack of finance. Similar to Hararghe Zone [5] and a study in Gondar [10], there was incidence of stock outs in more than half of the institutions $(n=6)$ during the last three months but unlike the study in Hararghe which showed nil incidence of over stocks [5], there was incidence of over stocks in the last three months in three of all institutions in this study. The difference might be due to the studies were conducted at different time and place. Comparably to Hararghe [5] but opposite to a study in India [18], there were expired commodities in four of the institutions in the last three months.

In six of the institutions, quantities on inventory records were properly matched with the physical count but three institutions had appropriately recorded price of each item on stock record card; however only half $(n=5)$ institutions had stock record card. Most of the institutions $(n=8)$ had standard guide line for commodities inventory management in their stores. Opposite to a study in India which showed absolute unavailability of bin cards and stock record cards [13] but similar to a study in West Hararghe Zone [5], this study found that bin cards and invoices were available in all institutions whereas stock cards were not available in 5 of them. RRF, IFRR and LMIS formats were available in nine of the institutions however less of them $(n=6)$ had separate records for all items. Three of the institutions had detailed written inventory instructions and procedures but none of the institutions had electronic data interchange technology and data base of suppliers.

Only two institutions (20\%) completely controlled and operated their stores by pharmacists but the rest by druggists which is opposite to a study in India at which $65 \%$ of the health centers were operated by pharmacists [13]. This may be because of the difference in the availability of educated human resource. Slightly similar to a study in Hararghe [5] which showed complete absence but strictly opposite to most standards, only two institutions had functional wall thermometers. Calibrated hygrometer to manage humidity and fire extinguishers in case of fire emergency were not available in all and seven institutions respectively; in contrast, only one institution had fire proof area for combustibles. In most institutions ( $n=$ 8), secured storage of controlled drugs were absent. This is contradictory to most standards specifically to Food, Medicine and Health care Authority of Ethiopia (FMHACA) currently Ethiopian food and drug administration authority (EFDA) [4]. This might be because of lack of follow-up and supervision from the regulatory bodies. Most stores $(n=9)$ were protected from water penetration and six of the stores were properly shelved, clean \& dry, ventilated \& out of direct sunlight, but opposite to a study in Hararghe [5], storage by FEFO policy was not used by most $(n=7)$ of the institutions; however cold storage management and maintenance was good in all institutions. Cartons were stacked at least $10 \mathrm{~cm}$ off the floor in most $(n=7)$ of the institutions. Opposite to the pharmaceuticals supply and fund agency (PFSA), 
EPSA standard [2] which instructs that each shelf should be arranged $30 \mathrm{~cm}$ away from the wall and other stacks and no more than $2.5 \mathrm{~m}$ high; shelves were aligned in contact with each other in eight institutions and cartons touched ceiling was visible in four institutions. Cartons were arranged disorderly in half of the institutions $(n=5)$. Unusable items were properly sorted in seven institutions which could be expected from all but corrosives and combustibles held with medicines in eight institutions. Six institutions had sufficient space to facilitate free and conducive stock trafficking.

\section{Conclusion}

The inventory management, recording and store keeping practices were not satisfactory in the institutions. Calculation fallacies, recording errors, improper stock levels maintenance, lack of automatic recording, absence of wall thermometers, absence of humidity and fire control systems, absence of lockable cabinets, fail to use FEFO storage technique and holding combustibles with drugs were found to be the major pitfalls of these institutions.

\section{List Of Abbreviations}

BC: Bin Card; EFDA: Ethiopian Food and Drug Administration Authority; EPSA: Ethiopian Pharmaceuticals Supply Agency; FEFO: First-to-Expire, First-Out; FMHACA: Food, Medicine and Health care Authority of Ethiopia; IFRR: Internal Facility Report and Resupply Form; LMIS: Logistic Management and Information System; PFSA: Pharmaceuticals Supply and Fund Agency; RRF: Report and Requisition Form; SRC: Stock Record Card; USAID: United States Agency for International Development and WHO: World Health Organization

\section{Declarations}

\section{Ethics approval and consent to participate}

The study was approved by "Ethical Review Committee" of Department of Pharmacy in Medicine and Health Science College of Wollo University. Written informed consent was secured from all participants. No personal identifiers used during data collection. Data was analyzed and held confidentially.

\section{Consent for publication}

Not applicable.

\section{Availability of data and materials}

The data and materials for the current study are available from the corresponding author with reasonable request.

\section{Competing interests}


The authors declare that they have no competing interests.

\section{Funding}

This research was funded by Tropical College of Medicine, Dessie campus.

\section{Authors' contributions}

EMB (mekashawe@gmail.com) accomplished the data collection and processing as well as analysis and interpretation of the result; MHK (yeabdrug@gmail.com) involved in the design, literature search and provided supervision and BDW (birdpharma@gmail.com) participated in the literature review and writing stage of the research. All authors approved the manuscript for submission.

\section{Acknowledgements}

Not applicable.

\section{References}

1. USAID/DeliverProject. The Logistics Handbook: A Practical Guide for the Supply Chain Management of Health Commodities, Second edition edn; 2011. Available from: http://apps.who.int/medicinedocs/documents/s20211en/s20211en.pdf.

2. PFSA. Standard operating procedure manual for the integrated pharmaceutical logistics system in health facilities of Ethiopia, 2nd Edition. 2015. Available from:

https://epsa.gov.et/download/standard-operating-procedures/?wpdmdl=2287\&ind=e1y7QTiOXo-yz5BFj5Y7K1UDCv04I53aGUoxOSbd1G2HkIBpe9e3_eedD5t5ra0.

3. Embrey MA. MDS-3: managing access to medicines and health technologies. Sterling, VA: Kumarian Press; 2013. Available from:

https://apps.who.int/medicinedocs/documents/s19577en/s19577en.pdf.

4. FMHACA. Standard operating procedures for pharmaceuticals good distribution and storage practices. 2018. Available from: http://www.fmhaca.gov.et/publication/standard-operatingprocedures-for-pharmaceuticals-good-distribution-and-storage-practices/.

5. Kassie GM, Mammo S. Assessment of pharmaceutical store management in Woreda health offices of west Hararghe zone, Ethiopia. Int Res J Pharm 2014, 5(8):642-645. DOI: 10.7897/22308407.0508131. Available from: http://www.irjponline.com/admin/php/uploads/2223_pdf.pdf.

6. Snow J. Guidelines for the storage of essential medicines and other health commodities: USAID; 2003. Available from: https://www.jsi.com/JSIInternet/Inc/Common/_download_pub.cfm? $\mathrm{id}=10503 \&$ lid $=27$.

7. Vriesendorp S, Peza LDI, Perry GP, Seltzer JB, O'Neil M, Reimann S, Gaul NM, Barraclough A, LeMay N, Buxbaum A. Health systems in action: an ehandbook for leaders and managers; 2010. Available from: http://www.msh.org/sites/msh.org/files/msh_ehandbook_complete.pdf. 
8. Ali AK. Inventory management in pharmacy practice: a review of literature. Arch Pharm Pract 2011, 2(4):151-156. Available from: https://doaj.org/article/e5f436a3868440d49bc47d09ee704da8.

9. Dwivedi S, Kothiyal P. Inventory management: A tool of identifying items that need greater attention for control. Pharma Innov 2012, 1(7, Part A):125-129. Available from: http://www.thepharmajournal.com/vol1/ssue7/Issue_sept_2012/14.1.pdf.

10. Fentie M, Fenta A, Moges F, Oumer H, Belay S, Sebhat Y, Atinafu T, Mekonnen T, Somasundaram J. Availability of Essential Medicines and Inventory Management Practice in Primary Public Health Facilities of Gondar Town, North West Ethiopia. J PharmaSciTech 2015, 4(2):54-56. Available from: https://www.researchgate.net/publication/298708705.

11. Mohamed A-AM, Ahmed AS. Enhancing the Inventory Control Effectiveness of a Pharmaceutical Distributor in Egypt: A Case Study. J Supply Chain Oper Manag 2016, 14(2):23-35. Available from: https://www.csupom.com/uploads/1/1/4/8/114895679/vol14no2_p3.pdf.

12. Pallangyo NP. The analysis of the performance of medical stocks control system: a case of Dodoma regional hospital. 2014:88. Available from: http://repository.out.ac.tz/id/eprint/501.

13. Kokilam MB, Joshi HG, Kamath VG. Assessment of Pharmaceutical Store and Inventory Management in Rural Public Health Facilities - A study with reference to Udupi District, Karnataka. Pharm Methods 2015, 6(2):53-59. DOI: 10.5530/phm.2015.6.7. Available from: http://phmethods.net/article/165.

14. Adzimah ED, Awuah-Gyawu M, Aikins I, Duah PA. An assessment of health commodities management practices in health care delivery; a supply chain perspective. The case of selected hospitals in Ashanti region-Ghana. Eur J Bus Soc Sci 2014, 3(8):78-103. Available from: http://europub.co.uk/articles/10504/view.

15. Nahamya D. Assessment of essential drug management in the public health facilities in Uganda. PhD Thesis. University of Cape Town; 2007. Available from: https://open.uct.ac.za/handle/11427/9460.

16. Hani U, Basri MH, Winarso D. Inventory Management of Medical Consumables in Public Hospital: a case study. Management 2013, 3(2):128-133. DOI: 10.5923/j.mm.20130302.10. Available from: http://article.sapub.org/10.5923.j.mm.20130302.10.html.

17. Leung N-HZ, Chen A, Yadav P, Gallien J. The Impact of Inventory Management on Stock-Outs of Essential Drugs in Sub-Saharan Africa: Secondary Analysis of a Field Experiment in Zambia. PLOS ONE 2016, 11(5):e0156026. DOI: 10.1371/journal.pone.0156026. Available from: https://dx.plos.org/10.1371/journal.pone.0156026.

18. Iqbal MJ, Geer MI, Dar PA. Indicator Based Assessment of Medicine Storage and Inventory Management Practices in various Public Sector Hospitals of District Srinagar. Int Arch Biomed Clin Res 2015, 1(2):8-15. Available from: https://iabcr.org/index.php/iabcr/article/view/236. 